\title{
Changes in the soil microbial community with a pine plantation restoration in a dry valley of the upper reaches of the Minjiang River, southwest China
}

\author{
Zhanfeng Liu, ${ }^{1,2}$ Guohua Liu, ${ }^{1}$ Bojie Fu, ${ }^{1}$ Yaqiong Wu, ${ }^{1}$ Huifeng Hu, ${ }^{1}$ and Shenglei Fu ${ }^{2}$ \\ ${ }^{1}$ State Key Laboratory of Urban and Regional Ecology, Research Center for Eco-environmental Sciences, Chinese Academy \\ of Sciences, Beijing, China. ${ }^{2}$ Institute of Ecology, South China Botanical Garden, Chinese Academy of Sciences, Guangzhou, \\ China \\ Address for correspondence: Bojie Fu, State Key Laboratory of Urban and Regional Ecology, Research Center for \\ Eco-Environmental Sciences, Chinese Academy of Sciences, P.O. Box 2871, Beijing 100085, China. Voice: \\ +86-10-62923557; fax: +86-10-62923557. bfu@rcees.ac.cn
}

The objective of this study was to investigate the changes in soil microbial biomass $\mathrm{C}$, microbial metabolic activity, functional diversity, and metabolic diversity pattern during the restoration process of a pine (Pinus tabulaeformis) plantation. In this study, a chronosequence approach was adopted. Three sites of pine plantations along a restoration chronosequence (12 years old (PF12), 25 years old (PF25), 35 years old (PF35)), and their paired reference sites of natural shrub community (Shrub1, Shrub2, and Shrub3) were selected. Soil microbial biomass C increased and microbial quotient declined with pine plantation age. Microbial metabolic activity, as measured by average well color development (using Biolog $\mathrm{GN}_{2}$ plates), exhibited a decline along the restoration chronosequence with values ranked as PF12 > PF35 > PF25 in topsoil and PF12 > PF25 > PF35 in subsoil. Functional diversity, as estimated by substrate diversity and substrate richness, exhibited a pattern similar to the metabolic activity. Principal component analysis indicated that metabolic diversity followed recognized patterns along the restoration chronosequence with PF12 significantly different from PF25 and PF35. There was an apparent reduction of microbial metabolic activity and functional diversity during pine plantation restoration, which can be explained by a general decline in soil nutrient availability, particularly $\mathrm{C}$ availability, and soil $\mathrm{pH}$ associated with the establishment of a coniferous species.

Keywords: microbial metabolic activity; microbial functional diversity; pine plantation; restoration chronosequence; microbial biomass C; microbial quotient

\section{Introduction}

The soil microbial communities play key roles in ecosystems and mediate many ecological processes that are central to ecosystem functioning, including nutrient cycling, organic matter decomposition, and carbon cycling (Schimel 1995). Studies have reported that the soil microbial community is a more sensitive component of the terrestrial ecosystem to disturbance than plants and animals in forest ecosystems (Panikov 1999). The size, composition, and activity of the soil microbial community can also reflect the impacts of ecosystem types and management strategies upon them. At the same time, management strategies and restoration approaches can significantly affect the structure and function of soil microbial communities. Therefore, the soil microbial community can provide invaluable information for ecosystem restoration, and it has been used as an indicator of restoration process in degraded land (Harris 2003).

Soil microbial biomass and metabolic diversity patterns are two major components of soil microbial communities (Rogers and Tate 2001). Soil microbial biomass is the living and active part of the soil organic matter, the source and sink of available nutrients (Diaz-Ravina et al. 1993). Soil microbial biomass can respond rapidly to changes in soil management practices, so it has been recommended as a useful ecological indicator of environmental stress caused by anthropogenic activities. Soil microbial quotient (the soil microbial biomass 
carbon: soil organic carbon ratio) has been used as an indicator of future changes of soil organic matter status in response to external disturbance. It was reported that the role of microbial biomass in soil organic matter deposition and $\mathrm{N}$ turnover is significant, particularly in disturbed and/or regenerating ecosystems (Arunachalam et al. 1996). Arunachalam and Pandey (2003) characterized the altitudinal and successional trends in soil microbial biomass during the vegetation recovery of the abandoned cultivation systems, and pointed out that the altitudinal and successional dynamics of soil microbial biomass carbon and nitrogen were linked to soil organic matter and total nitrogen (TN) contents in the soil during community development after abandonment. Jia et al. (2005) investigated soil microbial biomass and nutrients in soil at a secondary forest chronosequence and found that soil microbial biomass carbon increased quickly, and reached the maximum in a 17 -year-old secondary forest; but it decreased and remained at a stable level thereafter.

The diversity of the soil microbial community also plays an important role in soil ecosystem function maintenance. Microbial metabolic diversity pattern, estimated by using Biolog method, is a better indicator for evaluating the functional changes in soil microbial community than the soil microbial biomass. In spite of various limitations, Biolog method has been widely used to characterize microbial communities associated with various crop types and tree species in agricultural, grassland and forest soils (White et al. 2005).

The dry valley of the upper reaches of Minjiang River is the key region for rebuilding the ecological protective barrier for the upper Changjiang River in Southwest China. The main ecological issues in this area were vegetation cover decreasing, and soil and water loss, which further deteriorate the hydrological condition and induce the occurrence of natural disasters, such as landslides. Environment degradation also hinders the economic development of this area. Therefore, urgent issue for the area is to restore the degraded ecosystems by ecological approaches, particularly for vegetation restoration. Many restoration studies have been conducted in this area, however, most of which mainly focused on vegetation types, plant community structure, plant diversity, and their impact on soil properties and nutrient cycling (Pan and Liu 1998; Wu et al.
2001;Pang et al. 2002), little information is available on how the soil microbial community might change during the plantation restoration process. During the vegetation restoration process, large changes in plant diversity, composition, and production occur (Chen et al. 2003; Chen and Li 2004) and lead to the hypothesis that these changes should also affect the biomass and structure of the soil microbial community. On the basis of the analysis above, this paper aimed to investigate the changes in soil microbial community during the restoration process of a pine plantation and to enhance our understanding of how aboveground and belowground component of the ecosystem interact when plantations are established on the degraded land.

\section{Materials and methods}

\section{Study area}

The study area is located at Mao County, Sichuan Province, Southwestern China (103 $41^{\prime} 06^{\prime \prime}$ $103^{\circ} 44^{\prime} 27^{\prime \prime} \mathrm{E} ; 31^{\circ} 37^{\prime} 20^{\prime \prime}-31^{\circ} 44^{\prime} 53^{\prime \prime} \mathrm{N}$, and 1500 $3090 \mathrm{~m}$ asl.) (Fig. 1). This area was the central part of the dry valley of upper reaches of Minjiang River, which is one of the four principal tributaries of the Changjiang river. The landform of this area is river-cut canyons and mountains. The mean annual temperature is $11.0^{\circ} \mathrm{C}$, and mean annual precipitation is $494.8 \mathrm{~mm}$. Mean annual evaporation is $1356 \mathrm{~mm}$. The aridity index (the ratio of potential maximum evaporation to rainfall) for this area is 1.92, which is typical of semiarid environments (Zhu and Li 1989). Brown soil is the predominant soil type. The original native vegetation of this area was forest. Because of extensive deforestation and destruction, the forest cover was decreased from 50\% in the Yuan dynasty (1297 A.D. -1341 A.D.), $30 \%$ in 1949 , to $18 \%$ in 1980 (Li 1990). Consequently, most of the forests in this area were degraded into a secondary shrub community (Quercus aliena var. acuteserrata and Corylus heterophylla) (Li 1990). Starting in the late 1950s, large-scale plantations were established in the area. The plantations were established predominantly on the shrubland and a majority of the plantations were composed of $P$. tabulaeformis, $P$. armandi, and Picea asperata. The plantations were established from seedlings and by aerial planting. In this study, the chronosequence approach was adopted. Three sites of pine plantations along a 


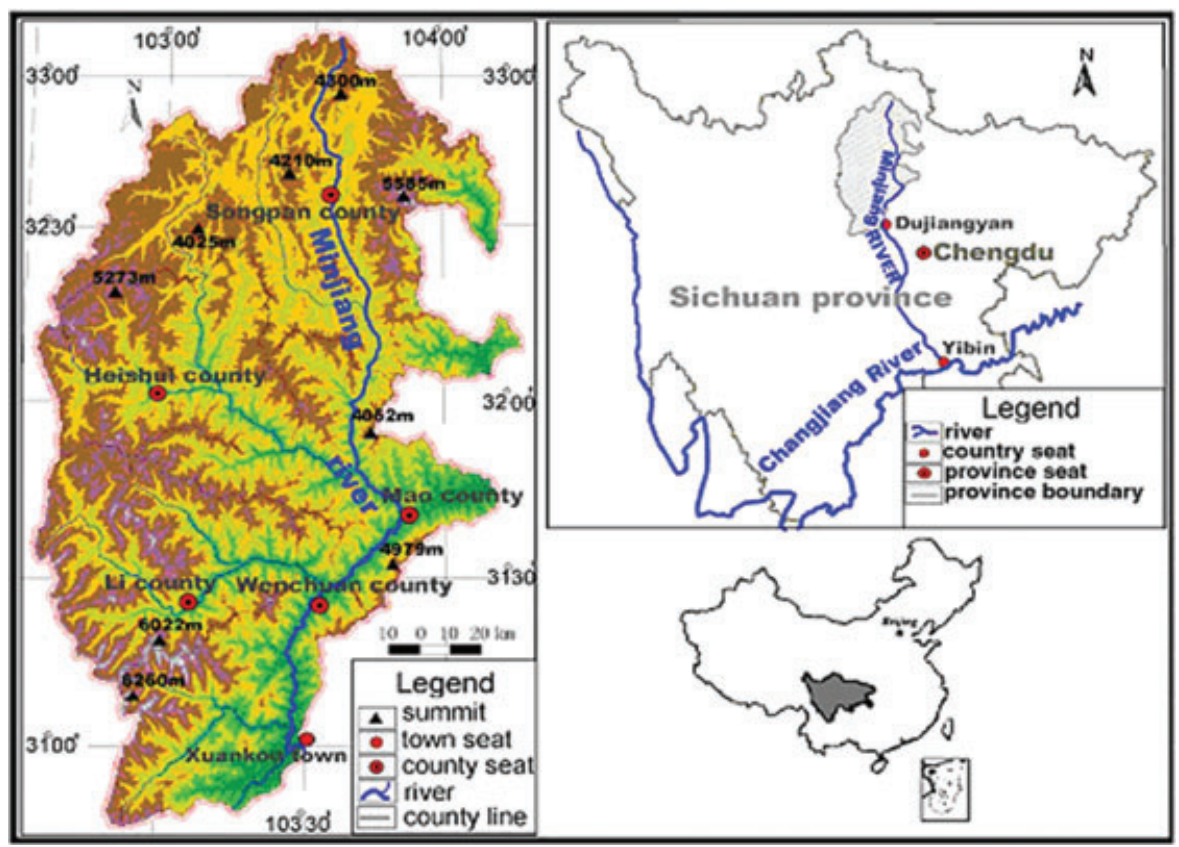

Figure 1. The location of the study area (modified from Li et al. (2006)).

restoration chronosequence (12 years old (PF12), 25 years old (PF25), 35 years old (PF35)), and their paired reference sites of natural shrub community (Shrub1, Shrub2, and Shrub3) were selected. The detail descriptions about plant community characteristics for these selected sites were listed in Table 1. All the sites have similar topography and soil type to minimize site differences.

\section{Soil sampling and vegetation survey}

Topsoil $(0-10 \mathrm{~cm})$ and subsoil $(10-20 \mathrm{~cm})$ samples were collected in April, July and October 2005 from three replicate plots $(20 \mathrm{~m} \times 20 \mathrm{~m})$ at each site as described above. The distances between any two of these replicate plots exceeded $100 \mathrm{~m}$. The samples in each plot were collected randomly from five points and mixed into one composite sample. After carefully removing the surface organic matter and plant roots, each bulked sample was halved. One half was air-dried for the analysis of soil physicochemical properties, the other half was passed through a 2-mm sieve, placed in sealed plastic bags, kept on ice, transported to the laboratory, and stored at $4^{\circ} \mathrm{C}$ for microbial assays. Microbial assays were conducted within $48 \mathrm{~h}$ of sampling.
Vegetation survey was also conducted in the sample plots $(20 \mathrm{~m} \times 20 \mathrm{~m})$ at each site. In these sample plots, all tree species were identified and measured for layer coverage, DBH (diameter at breast height), total height, and frequency. Within each sample plot, five $5 \mathrm{~m} \times 5 \mathrm{~m}$ quadrats on the diagonal line were chosen, where shrub species were identified and measured for layer coverage, base diameter, total height. Within each $5 \mathrm{~m} \times 5 \mathrm{~m}$ quadrat, one $1 \mathrm{~m} \times 1 \mathrm{~m}$ quadrat was set up to identify herb species and measure for layer coverage and height.

\section{Soil physicochemical properties}

The methods used for the analysis of soil physicochemical properties were adopted from Lu (1999). Soil $\mathrm{pH}$ was determined in 1: 2.5 soil: water slurry using a combination glass electrode. The bulk density of the soils was determined by the core method. Soil organic carbon (SOC) was determined by the potassium dichromate titration method after digestion. TN was determined by the semimicro Kjeldahl method. Total phosphorus (TP) was determined colorimetrically after wet digestion with $\mathrm{H}_{2} \mathrm{SO}_{4}$ plus $\mathrm{HClO}_{4}$. 
Table 1. Description of plant community properties under paired pine plantation and shrub vegetation plots

\begin{tabular}{|c|c|c|c|c|c|}
\hline Site & $\begin{array}{l}\text { Height } \\
(\mathrm{m})\end{array}$ & $\begin{array}{l}\text { DBH or } \\
\text { Base } \\
\text { diameter } \\
(\mathrm{cm})\end{array}$ & $\begin{array}{l}\text { Plant } \\
\text { density } \\
\text { (plants } \\
\mathrm{ha}^{-1} \text { ) }\end{array}$ & $\begin{array}{c}\text { Layer } \\
\text { coverage) } \\
(\%)\end{array}$ & Plant composition \\
\hline PF12 & 7.57 & 9.42 & 2133 & 70 & $\begin{array}{l}\text { A: Pinus tabulaeformis; } \mathrm{S}: 35 \% \text { layer coverage, } \\
0.88 \mathrm{~m} \text { height, } 0.47 \mathrm{~cm} \text { base diameter, } \\
31,200 \text { plants } \mathrm{ha}^{-1} \text {, main species: Quercus } \\
\text { aliena var. acuteserrata, Lespedeza bicolor, } \\
\text { Corylus heterophylla; } \mathrm{H}: 17 \% \text { layer } \\
\text { coverage, } 17.28 \mathrm{~cm} \text { height, } 75,4000 \text { plants } \\
\text { ha }^{-1} \text {, main species: Carex } \\
\text { enervis,Epimedium brevicornu, Thalictrum } \\
\text { aquilegifolium }\end{array}$ \\
\hline PF25 & 11.65 & 12.45 & 2133 & 80 & $\begin{array}{l}\text { A: Pinus tabulaeformis; } \mathrm{S}: 40 \% \text { layer coverage, } \\
1.31 \mathrm{~m} \text { height, } 0.53 \mathrm{~cm} \text { base diameter; } \\
\text { 17,520 plants } \mathrm{ha}^{-1} \text {, main species: Quercus } \\
\text { aliena var. acuteserrata, Lespedeza bicolor, } \\
\text { Corylus heterophylla; } \mathrm{H}: 35 \% \text { layer } \\
\text { coverage, } 20.76 \mathrm{~cm} \text { height, } 9,66,000 \text { plants } \\
\text { ha }{ }^{-1} \text {, main species: Pteris cretica, } \\
\text { Cimicifuga foetida, Carex enervis }\end{array}$ \\
\hline PF35 & 13.88 & 13.88 & 2000 & 90 & $\begin{array}{l}\text { A: Pinus tabulaeformis; } \mathrm{S}: 40 \% \text { layer coverage, } \\
1.42 \mathrm{~m} \text { height, } 0.77 \mathrm{~cm} \text { base diameter, } \\
18,160 \text { plants ha }{ }^{-1} \text {, main species: Salix } \\
\text { oritrepha, Lespedeza bicolor, Corylus } \\
\text { heterophylla; } \mathrm{H}: 31.4 \% \text { layer coverage, } \\
23.27 \mathrm{~cm} \text { height, } 8,00,000 \text { plants ha }{ }^{-1}, \\
\text { main species: Pteris cretica, Deyeuxia grata }\end{array}$ \\
\hline Shrub1 & 1.04 & 1.03 & 26,800 & 90 & 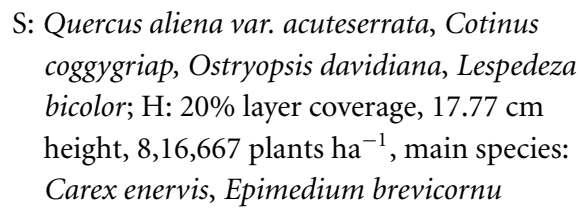 \\
\hline Shrub2 & 1.52 & 0.82 & 22,400 & 90 & $\begin{array}{l}\text { S: Quercus aliena var. acuteserrata, Corylus } \\
\text { heterophylla,Lespedeza bicolor; } \mathrm{H}: 14.33 \% \\
\text { layer coverage, } 22.26 \mathrm{~cm} \text { height, } 8,90,000 \\
\text { plants } \mathrm{ha}^{-1} \text {, main species: Deyeuxia grata, } \\
\text { Carex enervis, Pteris cretica }\end{array}$ \\
\hline Shrub3 & 0.9 & 0.27 & 17,600 & 40 & $\begin{array}{l}\text { S: Quercus aliena var. acuteserrata, Corylus } \\
\text { heterophylla, Lespedeza bicolor; } \mathrm{H}: 49.4 \% \\
\text { layer coverage, } 26.17 \mathrm{~cm} \text { height, } 9,46,000 \\
\text { plants ha }{ }^{-1} \text {, main species: Pteris cretica, } \\
\text { Astilbe chinensis }\end{array}$ \\
\hline
\end{tabular}

$D B H$ diameter at breast height, $A$ arbor layer, $S$ shrub layer, $H$ herb layer, $P F 12$ 12-year-old pine plantation, $P F 25$ 25-year-old pine plantation, PF35 35-year-old pine plantation, Shrub1, Shrub2, Shrub3 the paired shrub community for each pine plantation site, respectively. 


\section{Soil $\mathrm{CO}_{2}$ emission}

Soil $\mathrm{CO}_{2}$ emission was measured using a LI-COR soil $\mathrm{CO}_{2}$ emission chamber (model LI-6400-09; LICOR Biosciences, Lincoln, NE) and a LI-6400 infrared gas analyzer (LI-COR Biosciences). Five soil collars were positioned randomly in each plot and the soil $\mathrm{CO}_{2}$ emission was measured hourly for $24 \mathrm{~h}$ in April, July, and October in 2005. To minimize the $\mathrm{CO}_{2}$ emission from litter, the litterfall layer was removed, and then the PVC soil collars $(10.5 \mathrm{~cm}$ in internal diameter and $8 \mathrm{~cm}$ in height) were inserted $5 \mathrm{~cm}$ into the soil. The LI-6400 read five flux values at each time, and the average of these values was used as the mean soil $\mathrm{CO}_{2}$ emission rate of this interval. Soil temperature and soil water content (\%) were measured at the same time as the measuring of the soil $\mathrm{CO}_{2}$ emission rate. The soil temperature was measured at $5-\mathrm{cm}$ soil depth with a soil temperature probe (6000-09TC, LI-COR Inc., NE, $\pm 1.5^{\circ} \mathrm{C}, 0$ $50^{\circ} \mathrm{C}$ ). A TDR probe (ML2X, England, $\pm 0.01 \%$, $0-40^{\circ} \mathrm{C} ; \pm 0.02 \%, 40-70^{\circ} \mathrm{C}$ ) was used for determine the soil volumetric water content.

\section{Soil microbial community}

Soil microbial biomass C (SMBC) was determined by the chloroform fumigation method (Vance et al. 1987 ), using a $K_{c}=0.45$. The metabolic diversity patterns were measured using Biolog method (Garland and Mills 1991). The Biolog $\mathrm{GN}_{2}$ plates (Biolog Inc., Hayward, CA) used in our study contain 96 wells preloaded with a buffered nutrient medium and a tetrazolium violet redox dye (Biolog 1993). Each of the 95 wells additionally contains a different carbon source, the remaining well is left without a carbon source to function as a control. The moisture content of each soil sample was determined, which ensured that a constant equivalent dry-mass of soil was used for preparation of Biolog inoculum following 240-h incubation at $25^{\circ} \mathrm{C}$.

The method used for inoculum preparation was adopted from Zak et al. (1994b). Cell density of the inoculum can influence results because of the effect of cell numbers on the rates of color development. This can be minimized by analyzing the results at constant average well color development (AWCD). Following Zak et al. (1994b), the 95 different carbon sources were assorted to six groups: carbohydrates ( $\mathrm{CH}, n=28$ ), carboxylic acids (CA, $n=24)$, amino acids (AA, $n=20)$, miscellaneous (MI, $n=12$ ), polymers (PO, $n=5)$, and amides and amines (AM, $n=6)$. The AWCD was calculated as a measure of Biolog measurable metabolic activity either for individual substrate groups $\left(\mathrm{AWCD}_{\mathrm{S}}\right)$ or for all the mean of all substrates $\left(A W C D_{\mathrm{T}}\right)$. Functional diversity was measured as substrate diversity $(\mathrm{H})$, substrate richness (S) and substrate evenness (E). $S$ is the number of different substrates that used by the microbial community. H encompasses both substrate richness and the intensity of substrate use and quantified according to information theory (Magurran 1988). E measures the equitability of activity across all used substrates. Since well color was already fully developed after 48-h incubation, the Biolog plate data after 72-h incubation were used.

\section{Statistical analyses}

One-way ANOVA, ANCOVA, correlation analysis, and principal component analysis (PCA) were performed using SPSS 13.0 for Windows. Data that were not normally distributed were square-root or $\log$ transformed prior to analysis. When significance was observed at the $P<0.05$ level, Tukey's post hoc test was used for multiple comparison analysis. The Biolog microplate data after 72 -h incubation were compared by PCA. The plots of the principal component scores for each sample were used to display the differences in metabolic diversity patterns between soils through time.

\section{Results}

\section{Soil physicochemical properties}

At both sampling depths, SOC increased with the age of pine plantations, whereas the bulk density was found to decrease slightly in topsoil (Table 2). TN and TP exhibited a U-shaped trend: the values at PF25 were generally lower than at PF12 and PF35. However, soil C: $\mathrm{N}$ ratio exhibited a bell-shaped trend with the values at PF25 significantly higher than at PF12 and PF35 in topsoil. SOC, TN, and TP were positively correlated with plantation age, while $\mathrm{pH}$ and bulk density were negatively correlated with plantation age (Table 3). In addition, TN in PF 12 and SOC in PF 12 and PF35 were significantly different from the paired shrub community. However, no significant differences were observed for other soil properties between the pine plantations and the paired shrub community at each sampling site. 
Table 2. Some physiochemical parameters of the topsoil and subsoil under paired pine plantation and shrub vegetation plots

\begin{tabular}{|c|c|c|c|c|c|c|}
\hline Sites & $\begin{array}{c}\text { Bulk density } \\
\left(\mathrm{g} \mathrm{cm}^{-3}\right)\end{array}$ & $\mathrm{pH}$ & SOC (\%) & TN (\%) & $\mathrm{TP}\left(\mathrm{g} \mathrm{kg}^{-1}\right)$ & Soil C:N ratio \\
\hline \multicolumn{7}{|l|}{ Topsoil } \\
\hline PF12 & $1.17(0.21)$ & $7.08(1.16) \mathrm{ab}$ & $1.28(0.07) \mathrm{d}$ & $0.18(0.04) \mathrm{c}$ & $0.41(0.11) b c$ & $7.72(1.72) \mathrm{b}$ \\
\hline PF25 & $1.02(0.02)$ & $5.58(0.06) c$ & $2.29(0.11) \mathrm{c}$ & $0.16(0.02) \mathrm{c}$ & $0.21(0.01) \mathrm{d}$ & $15.08(2.15) \mathrm{a}$ \\
\hline PF35 & $0.95(0.07)$ & $6.11(0.33) b c$ & $3.53(0.03) \mathrm{b}$ & $0.41(0.05) \mathrm{b}$ & $0.60(0.01) \mathrm{a}$ & 8.65 (1.17) b \\
\hline Shrub1 & $1.12(0.26)$ & $8.08(0.08) \mathrm{a}$ & $2.74(0.03) b c$ & $0.31(0.03) b c$ & $0.56(0.02) a b$ & $8.85(0.16) b$ \\
\hline Shrub2 & $1.10(0.01)$ & $5.09(0.11) \mathrm{c}$ & $2.97(0.05) b c$ & $0.30(0.09) b c$ & $0.35(0.07) \mathrm{cd}$ & $10.72(3.40) \mathrm{ab}$ \\
\hline Shrub3 & $0.95(0.10)$ & $5.33(0.15) \mathrm{c}$ & $7.25(1.58) \mathrm{a}$ & $0.68(0.16) \mathrm{a}$ & $0.73(0.14) \mathrm{a}$ & $10.64(0.18) \mathrm{ab}$ \\
\hline \multicolumn{7}{|l|}{ Subsoil } \\
\hline PF12 & $1.28(0.10)$ & $7.30(1.32) a b$ & $1.00(0.08) b$ & $0.24(0.15)$ & $0.41(0.06) b c$ & $4.56(2.48) \mathrm{c}$ \\
\hline PF25 & $1.33(0.21)$ & $5.51(0.02) c$ & $1.11(0.08) \mathrm{b}$ & $0.10(0.03)$ & $0.17(0.02) \mathrm{d}$ & $10.84(3.61) \mathrm{a}$ \\
\hline PF35 & $1.03(0.05)$ & $6.19(0.09) b c$ & $2.38(0.01) \mathrm{b}$ & $0.29(0.01)$ & $0.54(0.01) \mathrm{ab}$ & $8.12(0.41) \mathrm{abc}$ \\
\hline Shrub1 & $1.18(0.05)$ & $8.31(0.05) \mathrm{a}$ & $1.34(0.02) \mathrm{b}$ & $0.25(0.06)$ & $0.55(0.01) \mathrm{ab}$ & $5.50(0.19) \mathrm{bc}$ \\
\hline Shrub2 & $1.28(0.19)$ & $5.36(0.17) \mathrm{c}$ & $1.73(0.02) \mathrm{b}$ & $0.17(0.03)$ & $0.26(0.04) c d$ & $10.22(1.77) \mathrm{ab}$ \\
\hline Shrub3 & $1.03(0.05)$ & $5.33(0.35) \mathrm{c}$ & $5.86(3.13) \mathrm{a}$ & $0.52(0.25)$ & $0.68(0.15) \mathrm{a}$ & $11.11(0.73) \mathrm{a}$ \\
\hline
\end{tabular}

Standard errors are in parentheses and values in the same column followed by the same letter are not significantly different at $P<0.05$.

$S O C$ soil organic carbon, $T N$ total nitrogen, $T P$ total phosphorus. For the abbreviations of sites see Table 1.

\section{Soil microbial biomass $\mathrm{C}$ and microbial quotient}

The SMBC in topsoil was significantly higher than that in subsoil (Fig. 2A). The SMBC at PF12 and PF35 was significantly lower than their paired shrub communities. The SMBC exhibited significantly correlations with plantation age, SOC, TN, TP, and bulk density (Table 3 ). The SMBC was significantly higher in PF35 than in PF12 and PF25 (Fig. 2A).

The soil microbial quotient (SMBC: SOC) under the pine plantations was generally higher than under the paired shrub communities in topsoil, whereas significant difference was only found between PF35 and its paired shrub community (Fig. 2B). For subsoil, the soil microbial quotient under the pine plantations was generally lower than under their paired shrub communities except for PF35. The soil microbial quotient was negatively correlated with plantation age and $\mathrm{TN}$, and positively correlated with $\mathrm{pH}$ and bulk density (Table 3 ). One-way ANOVA indicated that the soil microbial quotient showed significant differences between PF12 and other pine plantation sites $(F=112.79 ; P<0.01)$ with no significant difference between PF25 and PF35.

\section{Substrate utilization profiles of soil microbial communities}

The soil microbial metabolic activity, as measured by $\mathrm{AWCD}_{\mathrm{T}}$, showed differences with the age of the pine plantations (Fig. 3). However, pine plantations had similar microbial metabolic activities to the paired shrub communities with an exception at PF35 for topsoil. There was an apparent decline in $\mathrm{AWCD}_{\mathrm{T}}$ with the plantation age increasing and the values ranked as follow: PF12 > PF35 > PF25 (top soil) and PF12 > PF25 > PF35 (subsoil) (Fig. 3). Similar to SMBC and soil microbial quotient, the AWCD $_{\mathrm{T}}$ showed significant difference between PF12 and other pine plantation sites with no difference between PF25 and PF35.

In general, the microbial use of amides and amines (AM), polymers (PO), miscellaneous (MI), carboxylic acids (CA), amino acids (AA), and carbohydrates $(\mathrm{CH})$ seems to be retarded and the specific substrate metabolic activity $\left(\mathrm{AWCD}_{\mathrm{S}}\right)$ of the six substrate groups under PF25 and PF35 was significantly lower than PF12 (Fig. 4). However, only AWCD of $\mathrm{PO}, \mathrm{MI}, \mathrm{AA}$, and $\mathrm{CH}$ were significantly different between PF12 and other pine plantation sites. According to the correlation analysis, plantation age, 
Table 3. Significant results of the correlation analysis with microbial parameters used as dependent and plantation age and soil physicochemical parameters as independent variables

\begin{tabular}{|c|c|c|c|}
\hline $\begin{array}{l}\text { Plantation } \\
\text { age }\end{array}$ & $\mathrm{R}$ & $\begin{array}{c}\text { Bulk } \\
\text { density }\end{array}$ & $\mathrm{R}$ \\
\hline MI & $-0.482^{*}$ & MI & $0.544^{*}$ \\
\hline $\mathrm{CH}$ & $-0.518^{*}$ & $\mathrm{CH}$ & $0.587^{* *}$ \\
\hline $\mathrm{AWCD}_{\mathrm{T}}$ & $-0.450^{*}$ & $\mathrm{AWCD}_{\mathrm{T}}$ & $0.533^{*}$ \\
\hline SMBC & $0.906^{* * *}$ & SMBC & $-0.856^{* * *}$ \\
\hline SOC & $0.992^{* * *}$ & SMQ & $0.887^{* * *}$ \\
\hline SMQ & $-0.850^{* *}$ & & \\
\hline $\mathrm{BD}$ & $-0.992^{* * *}$ & $\mathrm{TP}$ & \\
\hline $\mathrm{pH}$ & $-0.675^{* *}$ & $\mathrm{H}$ & $0.576^{* *}$ \\
\hline $\mathrm{TN}$ & $0.812^{* *}$ & $S$ & $0.544^{*}$ \\
\hline \multirow[t]{2}{*}{$\mathrm{TP}$} & $0.492^{*}$ & $\mathrm{PO}$ & $0.496^{*}$ \\
\hline & & AA & $0.533^{*}$ \\
\hline $\mathrm{pH}$ & & SMBC & $0.736^{* * *}$ \\
\hline $\mathrm{H}$ & $0.569^{* *}$ & & \\
\hline S & $0.590^{* *}$ & $\mathrm{TN}$ & \\
\hline AM & $0.459^{*}$ & SMBC & $0.930^{* * *}$ \\
\hline $\mathrm{PO}$ & $0.675^{* *}$ & SMQ & $-0.494^{*}$ \\
\hline MI & $0.703^{* *}$ & & \\
\hline $\mathrm{CA}$ & $0.588^{* *}$ & SOC & \\
\hline $\mathrm{AA}$ & $0.774^{* * *}$ & SMBC & $0.941^{* * *}$ \\
\hline $\mathrm{CH}$ & $0.769^{* * *}$ & & \\
\hline $\mathrm{AWCD}_{\mathrm{T}}$ & $0.803^{* * *}$ & & \\
\hline SMQ & $0.823^{* * *}$ & & \\
\hline \multicolumn{4}{|c|}{ Soil C:N ratio } \\
\hline $\mathrm{H}$ & $-0.707^{* * *}$ & & \\
\hline S & $-0.701^{* *}$ & & \\
\hline AM & $-0.554^{* *}$ & & \\
\hline $\mathrm{PO}$ & $-0.724^{* * *}$ & & \\
\hline MI & $-0.564^{*}$ & & \\
\hline $\mathrm{CA}$ & $-0.582^{* *}$ & & \\
\hline $\mathrm{AA}$ & $-0.808^{* * *}$ & & \\
\hline $\mathrm{CH}$ & $-0.625^{* *}$ & & \\
\hline $\mathrm{AWCD}_{\mathrm{T}}$ & $-0.724^{* * *}$ & & \\
\hline
\end{tabular}

$T N$, total nitrogen; $T P$, total phosphorus; SOC, soil organic carbon; $S M B C$, soil microbial biomass carbon; $S M Q$, soil microbial quotient; $H$, substrate diversity; $S$, substrate richness; $A W C D_{T}$, microbial metabolic activity; $A M$, amides and amines; $P O$, polymers; $M I$, miscellaneous; $A A$, amino acids; $C A$, carboxylic acids; $C H$, carbohydrates.

$P$ levels: ${ }^{*}<0.05,{ }^{* *}<0.01,{ }^{* * *}<0.001$.

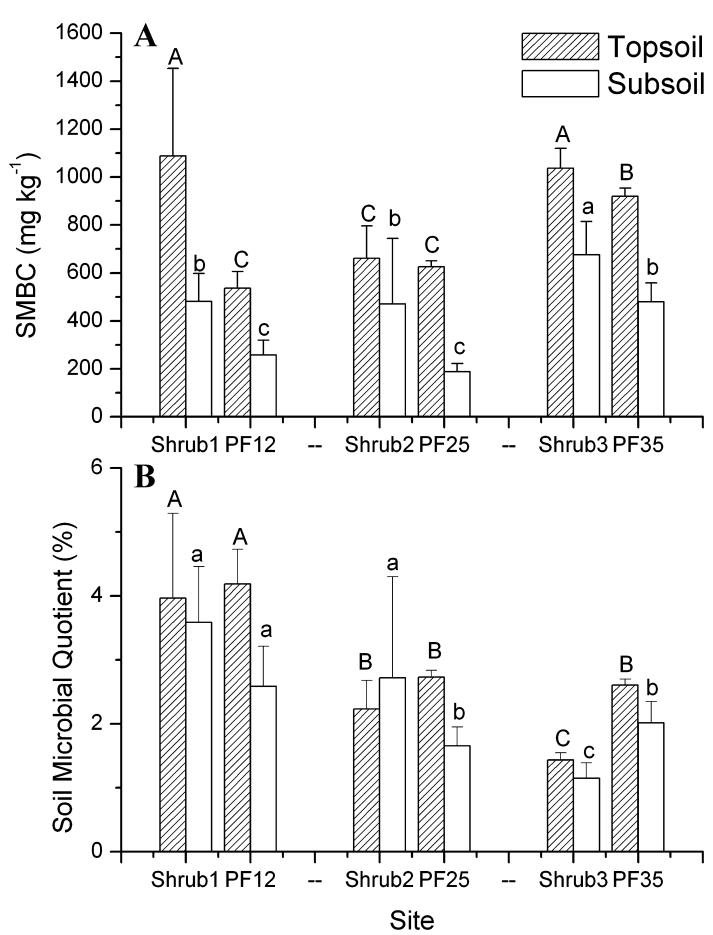

Figure 2. Changes in (A) soil microbial biomass $\mathrm{C}$ (SMBC) and (B) soil microbial quotient along a restoration chronosequence in pine plantations and their paired shrub vegetation plots. Bars represent standard errors of means. Within each data series, columns marked by the same letter are not significantly different at $P<0.05$. For the abbreviations of sites see Table 1 .

$\mathrm{pH}$, soil $\mathrm{C}$ : $\mathrm{N}$ ratio, bulk density, and $\mathrm{TP}$ are the major factors determining the Biolog measurable components of microbial community at the sites investigated (Table 3 ). The plantation age and soil C: $\mathrm{N}$ ratio was negatively correlated with $\mathrm{AWCD}_{\mathrm{T}}$ and $\mathrm{AWCD}_{\mathrm{S}}$ of several functional groups. Soil $\mathrm{pH}$ was positively correlated with $A W C D_{T}$ and $A W C D_{S}$ of the six functional groups. Soil bulk density was positively correlated with $\mathrm{AWCD}_{\mathrm{T}}$ and $\mathrm{AWCD}_{\mathrm{S}}$ of $\mathrm{MI}$ and $\mathrm{CH}$, and TP was positively correlated with $\mathrm{AWCD}_{S}$ of PO and AA (Table 3 ).

The decline in soil microbial metabolic activity during pine plantation restoration was also confirmed by the soil $\mathrm{CO}_{2}$ emission data (Fig. 5A). Our results also indicated that soil temperature and soil water content varied greatly among sampling sites (Fig. 5B). Soil $\mathrm{CO}_{2}$ emission decreased gradually with the age of pine plantation. ANCOVA indicated that the effect of plantation age on soil $\mathrm{CO}_{2}$ emission 


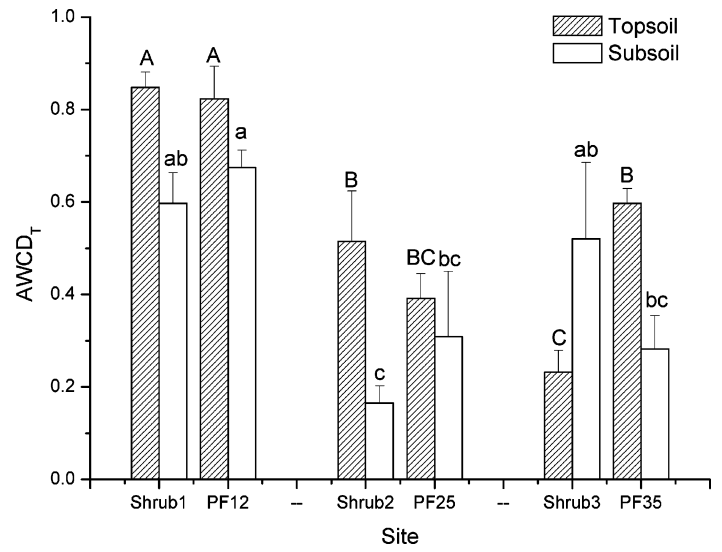

Figure 3. Average well color development of all substrates $\left(\mathrm{AWCD}_{\mathrm{T}}\right)$ in topsoil and subsoil along a restoration chronosequence in pine plantations and their paired shrub vegetation plots. Bars represent standard errors of means. Within each data series, columns marked by the same letter are not significantly different at $P<0.05$. For the abbreviations of sites see Table 1. was still significant $(F=9.936, P<0.001)$ when soil temperature $(F=706.158, P<0.001)$ and soil water content $(F=2.205, P=0.139)$ were included as covariates in the analysis. ANCOVA also suggested that soil temperature played an important role in explaining the variation of soil $\mathrm{CO}_{2}$ emission among the sampling sites.

Ordination biplots for PCA of Biolog data are shown in Figure 6. The different positions of the restoration chronosequences for the first two principal components indicated that there were large differences in the metabolic capability of the soil microbial community between sampling sites. For topsoil, PC1 and PC2 explained $40.1 \%$ and $17.7 \%$ of the variation in soil microbial community, respectively. An ANOVA of the PC1 scores obtained from topsoil indicated that PC1 scores were significantly different $(F=8.251 ; P<0.001)$ and mainly separated PF12 from PF25 and PF35. However, no significant differences were found between the PC2 scores $(F=1.580, P=0.199)$. For subsoil, PC1 and PC2 explained $61.3 \%$ and $10.0 \%$ of the variation in soil microbial community, respectively. The PCA results obtained from the subsoil were similar
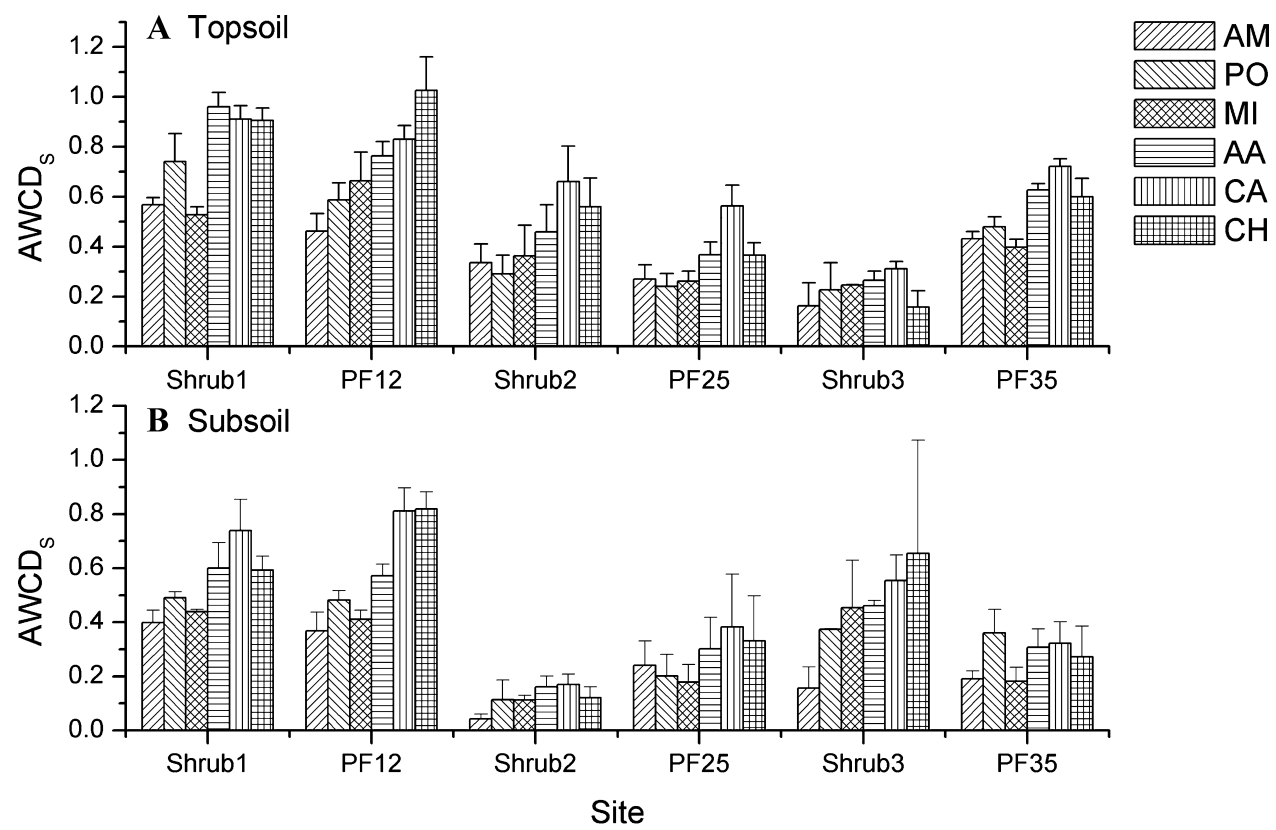

Figure 4. Average well color developments of the six substrate groups ( $\mathrm{AWCD}_{\mathrm{S}}$ ) in topsoil and subsoil along a restoration chronosequence in pine plantations and their corresponding shrub vegetation plots. Bars represent standard errors of means. AM, amides and amines; PO, polymers; MI, miscellaneous; AA, amino acids; CA, carboxylic acids; $\mathrm{CH}$, carbohydrates. For the abbreviations of sites see Table 1. 


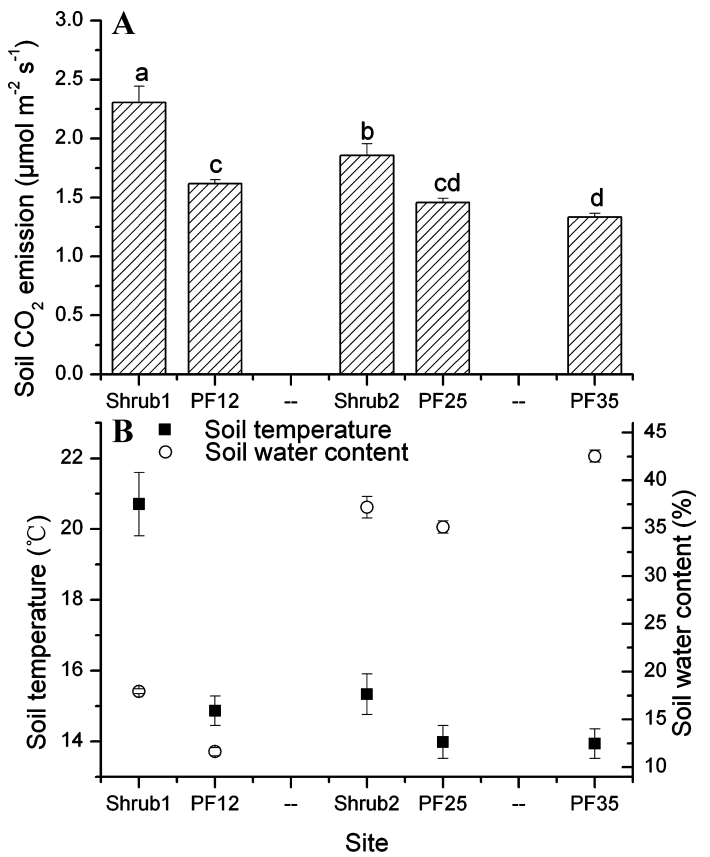

Figure 5. Changes in (A) soil $\mathrm{CO} 2$ emission and (B) soil temperature and soil water content along a restoration chronosequence in pine plantations and their paired shrub vegetation plots. Bars represent standard errors of means. Within each data series, columns marked by the same letter are not significantly different at $P<0.05$. For the abbreviations of sites see Table 1. The data for Shrub3 are not available.

to those from topsoil and the metabolic diversity patterns showed a significant separation along PC1 $(F=5.434 ; P=0.002)$ but not along PC2 $(F=0.819$; $P=0.548)$. $P F 12$ was again separated from $P F 25$ and PF35 along PC1.

Both pine plantations and their paired shrub communities at each site were similar in the functional diversity of the soil microbial community (Table 4). Substrate diversity and substrate richness showed a trend similar to microbial metabolic activity $\left(\mathrm{AWCD}_{\mathrm{T}}\right.$ and $\left.\mathrm{AWCD}_{\mathrm{S}}\right)$ and the values followed the order PF12 > PF35 > PF25 in both soil layers. However, substrate diversity and substrate richness were found significantly different between restoration chronosequences only in subsoil. The results of the correlation analyses suggested that soil $\mathrm{pH}$, soil $\mathrm{C}$ : $\mathrm{N}$ ratio and TP were the primary factors influencing the function diversity of the soil microbial community (Table 3 ).

\section{Discussions and conclusions}

Soil microbial biomass and microbial quotient The vegetation cover has substantial effects on soil properties, mainly due to its contribution to the accumulation of organic matter in soils (Rutigliano et al. 2004). There was an increase of SOC and a decrease of bulk density with increasing age of pine plantations. We also found that PF25 had lower TN and TP, and a higher soil C: $\mathrm{N}$ ratio than PF12 and $\mathrm{PF} 35$, which indicated that the availability of $\mathrm{N}$ and $\mathrm{P}$ was low under PF25 where soil N and P likely became limiting.

Soil microbial biomass reflects the degree of immobilization of $\mathrm{C}$ and $\mathrm{N}$. A decrease in soil microbial biomass could result in nutrient mineralization, while an increase in microbial biomass may lead to nutrient immobilization. The SMBC was significantly lower under pine plantations than their paired shrub communities. This can be attributed to a more diverse litter under the shrub community, which is able to support a larger and diverse microbial community (Nsabimana et al. 2004). The high content of phenols and other biochemicals in the litter of pine needles may inhibit microbial growth and activity (Nsabimana et al. 2004; Priha and Smolander 1997). SMBC increased with plantation age, SOC, TN and TP in this study, which was consistent with the studies reporting an increase in SMBC during plant primary (Insam and Haselwandter 1989) and secondary succession (Santruckova 1992). Changes in soil nutrients during pine plantation restoration can explain the increase in SMBC. In addition, this increase likely reflects the increase in above-ground net primary production which regulates the soil labile C content (Zak et al. 1994a). However, Aikio et al. (2000) observed a decrease in organic matter, soil microbial biomass and activity as well as soil nutrients along the primary succession in Finland, due to leaching of nutrients from the sandy mineral soil and thinning of the humus layer.

Soil microbial quotient, which can be interpreted as the portion of SOC immobilized in microbial cells, is a useful parameter for monitoring the soil organic matter and a sensitive index for measuring SOC or soil microbial biomass (Garcia et al. 2002). The soil microbial quotient declined with the age of plantation restoration. Similar trends have been 

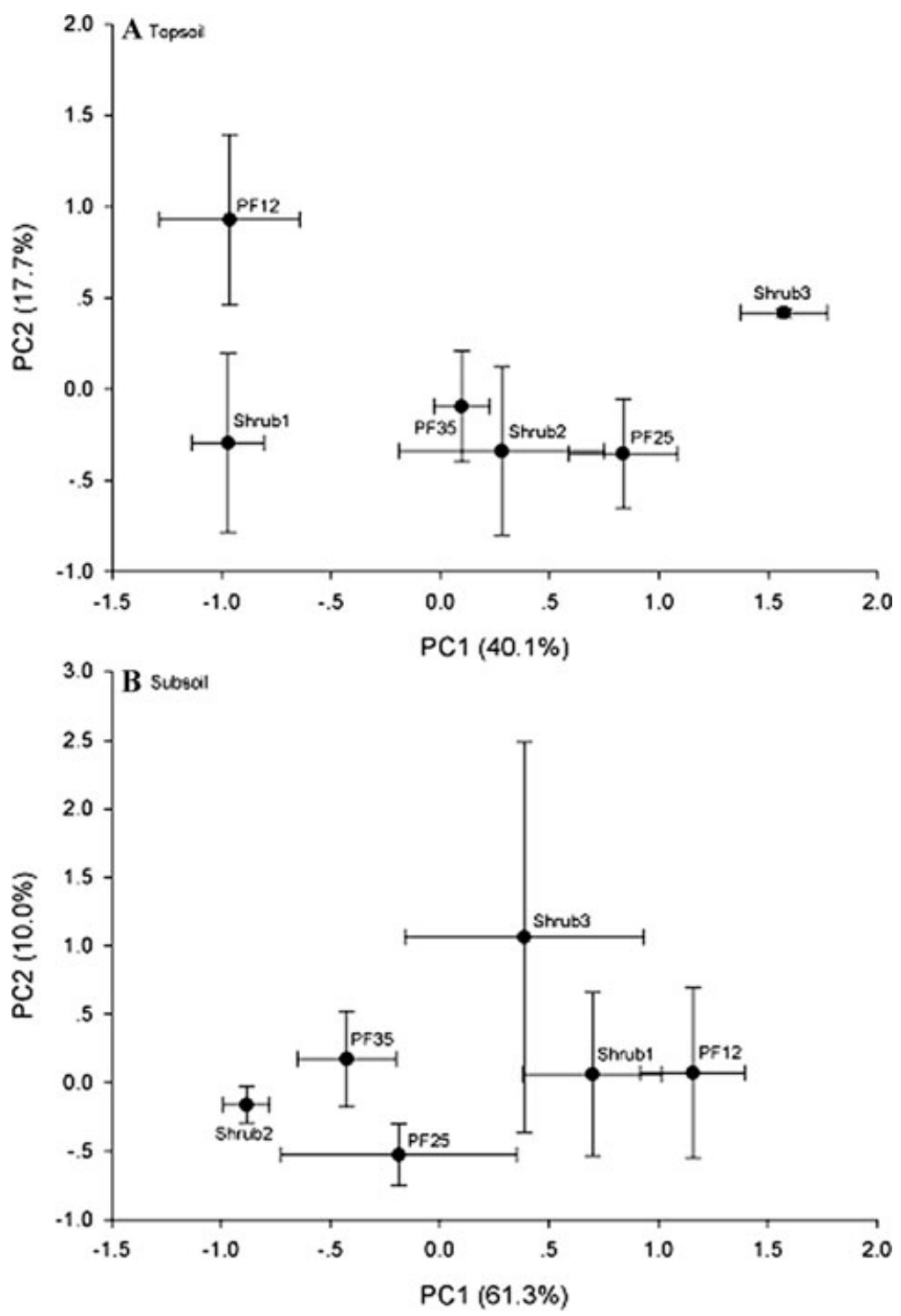

Figure 6. Principal components analysis of carbon utilization profiles (Biolog data after 72-h incubation) from (A) topsoil and (B) subsoil along a restoration chronosequence in pine plantations and their paired shrub vegetation plots. Bars represent standard errors of means. For the abbreviations of sites see Table 1.

observed during plant primary succession (Insam and Domsch 1988; Ding et al. 1992; Schipper et al. 2001). A high soil microbial quotient at the onset of restoration is likely due to the relatively high proportion of organic matter from fresh litter inputs being available to support the microbial community. Consequently, in early stages of restoration, the SMBC: SOC ratio is relatively high. Although the proportion of labile soil organic matter is high at the start of restoration, the absolute amount of available carbon is very low. As restoration proceeds, recalcitrant organic matter accumulates so that a smaller proportion of total soil organic matter is available to support the microbial community, and the soil microbial quotient declines. The microbial quotient was thus affected not only by the quantity, but also by the quality, of the carbon input. Other studies, however, have shown that the soil microbial 
Table 4. Microbial functional diversity as evaluated by substrate diversity, substrate richness, substrate evenness in topsoil, and subsoil samples under paired pine plantation and shrub vegetation plots

\begin{tabular}{lccc}
\hline Sites & Substrate diversity $\left(\mathrm{H}_{\mathrm{S}}\right)$ & Substrate evenness (E) & Substrate richness (S) \\
\hline Topsoil & & & \\
$\quad$ Shrub1 & $4.15(0.06)$ & $0.97(0.01)$ & $72.20(3.54) \mathrm{a}$ \\
PF12 & $4.07(0.02)$ & $0.97(0.01)$ & $67.17(1.82) \mathrm{ab}$ \\
Shrub2 & $3.41(0.46)$ & $0.94(0.02)$ & $47.67(9.70) \mathrm{cd}$ \\
PF25 & $3.74(0.11)$ & $0.97(0.01)$ & $50.00(5.07) \mathrm{bcd}$ \\
Shrub3 & $3.56(0.23)$ & $0.97(0.01)$ & $40.00(8.00) \mathrm{d}$ \\
PF35 & $4.03(0.03)$ & $0.97(0.01)$ & $64.13(1.86) \mathrm{abc}$ \\
Subsoil & & & $69.00(1.00) \mathrm{a}$ \\
Shrub1 & $4.11(0.02) \mathrm{a}$ & $0.97(0.01)$ & $61.33(1.02) \mathrm{ab}$ \\
PF12 & $3.98(0.02) \mathrm{a}$ & $0.97(0.01)$ & $20.00(5.42) \mathrm{d}$ \\
Shrub2 & $2.63(0.32) \mathrm{b}$ & $0.93(0.03)$ & $28.50(11.53) \mathrm{cd}$ \\
PF25 & $2.65(0.53) \mathrm{b}$ & $0.98(0.01)$ & $52.50(5.50) \mathrm{abc}$ \\
Shrub3 & $3.84(0.08) \mathrm{ab}$ & $0.96(0.01)$ & $36.00(8.10) \mathrm{bcd}$ \\
PF35 & $3.21(0.29) \mathrm{ab}$ & &
\end{tabular}

Standard errors are in parentheses and values in the same column followed by the same letter are not significantly different at $P<0.05$. For the abbreviations of sites see Table 1 .

quotient increases with increasing forest age (Bauhus et al. 1998).

\section{Soil microbial metabolic activity and functional diversity}

Soil microbial metabolic activity and diversity are important driving factors regulating biological, physical and biochemical processes in the ecosystem, which are central to ecosystem function (Finlay et al. 1997). Previous studies also demonstrated that soil microbial communities play an important role for successful plant establishment and plant community development during restoration processes (Noyd et al. 1995). The soil microbial community can metabolize a wide variety of carbon sources during the course of vegetation restoration, which is very important for organic matter turnover (Moynahan et al. 2002). Differences in microbial metabolic activity $\left(\mathrm{AWCD}_{\mathrm{T}}\right)$ and specific substrate metabolic activity $\left(\mathrm{AWCD}_{\mathrm{S}}\right)$ reflect the sole-carbon-source utilization ability and activity in the soil microbial community. Both $\mathrm{AWCD}_{\mathrm{T}}$ and $\mathrm{AWCD}_{\mathrm{S}}$ of the six substrate groups showed a decrease during pine plantation restoration. The decrease in metabolic activity can be explained by a general decline in nutrient availability, particularly $\mathrm{C}$ availability, and soil $\mathrm{pH}$ associated with the establishment of a coniferous species (Brais et al. 1995).
Similarly, Kreitz and Anderson (1997) pointed out that the decomposition of freshly fallen litter is retarded in acidic soils, because the ability of bacteria to degrade CA and other C sources is strongly reduced. The decline in soil metabolic activity was also confirmed by the data from soil $\mathrm{CO}_{2}$ emission. Since Soil $\mathrm{CO}_{2}$ emission represents the combined respiration of roots and soil microorganisms (Rustad et al. 2000), the decline in soil $\mathrm{CO}_{2}$ also supported that the microbial metabolic activity decreased during pine plantation restoration.

Compared with the measurements of species diversity, the functional diversity of soil microbial communities can provide more information about the soil functioning (Garland and Mills 1991). The diversity of decomposition functions performed by heterotrophic microorganisms represents one important component of microbial functional diversity. Metabolic diversity, as estimated by substrate diversity and substrate richness, showed a trend similar to metabolic activity. A reduction in metabolic diversity suggested the presence of a microbial community with a less resilient decomposition function particularly in response to external disturbance. It was expected that the patterns of soil metabolic diversity would be altered as a result of restoration changes of different pine plantations. This was confirmed by principal components analysis, which 
showed that the metabolic diversity patterns under PF12 were significantly different from that of PF25 and PF35. These differences might have reflected the differences in the ability of the microbial communities to metabolize different carbon sources at these sites. Furthermore, differences in carbon source utilization can be linked to differences in carbon source availability (Grayston et al. 1998). Soil pH, soil C: N ratio and TP were closely correlated with the substrate diversity and substrate richness, which revealed the role of soil characteristics in determining microbial communities in soils. Both microbial metabolic activity $\left(\mathrm{AWCD}_{\mathrm{T}}\right.$ and $\left.\mathrm{AWCD}_{\mathrm{S}}\right)$ and functional diversity were negatively correlated with soil $\mathrm{C}$ : $\mathrm{N}$ ratio, suggesting that the depression of several groups in spots of comparatively high $\mathrm{C}$ content in soils causes a more even distribution in substrate use. A possible explanation is that the accumulation of recalcitrant substrates has led to an impoverishment of the microbial community. This was consistent with the findings that some specialization of function occurs among microorganisms with increasing recalcitrance of SOM during later stages of the decomposition process (Ladd et al. 1996). We conclude that functional diversity loss during the process of pine plantation restoration could be explained by low $\mathrm{pH}$ caused by pine needle decomposition, leading to an accumulation in recalcitrant carbon in soils.

\section{Implications for restoration practices}

SOC and soil microbial biomass carbon under pine plantations were accumulating with increasing plantation age, suggesting that pine plantation restoration may be a satisfactory restoration practice from a perspective of soil carbon sequestration. However, there was an apparent reduction of microbial metabolic activity and functional diversity during pine plantation restoration, which caused by the decrease in $\mathrm{pH}$ and an accumulation in recalcitrant carbon in soils. The results indicated that pine plantation might not be the best choice in terms of the maintenance of microbial functional diversity. On May 12, 2008, an earthquake occurred right in the study area $\left(103.4^{\circ} \mathrm{E} ; 31.0^{\circ} \mathrm{N}\right)$ with a magnitude of 8.0. The earthquake has dramatically changed the landscape and destructed the vegetation. An urgent issue in the area is to restore the earthquake-damaged ecosystem, particularly for vegetation restoration. Since our work was done be- fore the earthquake, it will provide baseline data for the restoration of these damaged ecosystems.

\section{Acknowledgments}

This project was supported by National Basic Research Program of China (No.2009CB421104), the National Natural Sciences Foundation of China (No. 40621061 and No.40871248), and the Knowledge Innovation Program of South China Botanical Garden, Chinese Academy of Sciences.

\section{Conflicts of interest}

The authors declare no conflicts of interest.

\section{References}

Aikio, S., H. Vare \& R. Strommer. 2000. Soil microbial activity and biomass in the primary succession of a dry heath forest. Soil Biol. Biochem. 32: 1091-1100.

Arunachalam, A. \& H.N. Pandey. 2003. Ecosystem restoration of Jhum fallows in Northeast India: microbial C and $\mathrm{N}$ along altitudinal and successional gradients. Restor. Ecol. 11: 168-173.

Arunachalam, A. et al. 1996. The impact of disturbance on detrital dynamics and soil microbial biomass of a Pinus kesiya forest in north-east India. Forest Ecol. Manag. 88: 273-282.

Bauhus, J., D. Pare \& L. Cote. 1998. Effects of tree species stand age and soil type on soil microbial biomass and its activity in a southern boreal forest. Soil Biol. Biochem. 30: $1077-1089$

Biolog. 1993. Instructions for Use of Biolog GP and GN Microplates. Biolog. Hayward, CA.

Brais, S. et al. 1995. Changes in nutrient availability and forest floor characteristics in relation to stand age and forest composition in the southern part of the boreal forest of northwestern Quebec. Forest Ecol. Manag. 76: 181-189.

Chen, X.W. \& B.L. Li. 2004. Tree diversity change in remaining primary mixed-broadleaved Korean pine forest under climate change and human activities. Biodiversity Conserv. 13: 563-577.

Chen, X.W., B.L. Li \& Z.S. Lin. 2003. The acceleration of succession for the restoration of the mixed-broadleaved Korean pine forests in Northeast China. Forest Ecol. Manag. 177: 503-514.

Diaz-Ravina, M., M.J. Acea \& T. Carballas. 1993. Microbial biomass and its contribution to nutrient concentration in forest soils. Soil Biol. Biochem. 25: 25-31. 
Ding, M.M. et al. 1992. Effect of afforestation on microbial biomass and activity in soils of tropical China. Soil Biol. Biochem. 24: 865-872.

Finlay, B.J., S.C. Maberly \& J.I. Cooper. 1997. Microbial diversity and ecosystem function. Oikos 80: 209213.

Garcia, C. et al. 2002. Effect of plant cover decline on chemical and microbiological parameters under Mediterranean climate. Soil Biol. Biochem. 34: 635-642.

Garland, J.L. \& A. Mills. 1991. Classification and characterization of heterotrophic microbial communities on the basis of patterns of community-level sole-carbon-source utilization. Appl. Environ. Microb. 57: 2351-2359.

Grayston, S.J. et al. 1998. Selective influence of plant species on microbial diversity in the rhizosphere. Soil Biol. Biochem. 30: 369-378.

Harris, J.A. 2003. Measurements of the soil microbial community for estimating the success of restoration. Eur. J. Soil. Sci. 54: 801-808.

Insam, H. \& K.H. Domsch. 1988. Relationship between soil organic carbon and microbial biomass on chronosequences of the reclamation sites. Microbial Ecol. 15: 177188.

Insam, H. \& K. Haselwandter. 1989. Metabolic quotient of the soil microflora in relation to plant succession. Oecologia 79: $174-178$.

Jia, G.M. et al. 2005. Microbial biomass and nutrients in soil at the different stages of secondary forest succession in Ziwulin, Northwest China. Forest Ecol. Manag. 217: 117-125.

Kreitz, S. \& T.H. Anderson. 1997. Substrate utilization patterns extractable and non-extractable bacterial fractions in neutral and acidic beech forest soils. In Microbial Communities: Functional versus Structural Approaches. H. Insam \& A. Rangger, Eds.: 149-160. Springer. BerlinHeidelberg-New York.

Ladd, J.N. et al. 1996. Soil structure and biological activity. In Soil Biochemistry. G. Stotzky \& J.M. Bollag, Eds.: 23-77. Marcel Dekker. New York.

Li, A.N. et al. 2006. Eco-environmental vulnerability evaluation in mountainous region using remote sensing and GIS-A case study in the upper reaches of Minjiang River, China. Ecol. Model. 192: 175-187.

Li, C.B. 1990. Forest Ecological Research in Sichuan Province. Sichuan Science and Technology Press. Chengdu, China.

Lu, R.K. 1999. Analytical Methods of Soil Agrochemistry. Chinese Agriculture Science and Technology Press. Beijing.

Magurran, A.E. 1988. Ecological Diversity and its Measurement. Princeton University Press. Princeton, NJ.

Moynahan, O.S., C.A. Zabinski \& J.E. Gannon. 2002. Micro- bial community structure and carbon utilization diversity in a mine tailings revegetation study. Restor. Ecol. 10: $77-87$.

Noyd, R.K. et al. 1995. Native prairie grasses and microbial community responses to reclamation of taconite iron ore tailing. Can J. Bot. 73: 1645-1654.

Nsabimana, D., R.J. Haynes \& F.M. Wallis. 2004. Size, activity and catabolic diversity of the soil microbial biomass as affected by land use. Appl. Soil Ecol. 26: 81-92.

Pan, K.W. \& Z.G. Liu. 1998. Structures and dynamics of the tree layer of artificial mixed forests in clear-cut areas of subalpine dark coniferous forests. Chinese J. Appl. Environ. Biol. 4: 327-334 (In Chinese with English abstract).

Pang, X.Y. et al. 2002. Nutrient distribution and cycling of artificial and natural subalpine spruce forests in Western Sichuan. J. Appl. Environ. Biol. 1: 1-7 (In Chinese with English abstract).

Panikov, N.S. 1999. Understanding and prediction of soil microbial community dynamics under global change. Appl. Soil Ecol. 11: 161-176.

Priha, O. \& A. Smolander. 1997. Microbial biomass and activity in soil and litter under Pinus sylvestris, Picea abies and Betula pendula at two forest sites. Biol. Fert. Soils 33: $17-24$.

Rogers, B.F. \& R.L. Tate III. 2001. Temporal analysis of the soil microbial community along a toposequence in Pineland soils. Soil Biol. Biochem. 33: 1389-1401.

Rustad, L.E., T.G. Huntington \& R.D. Boone. 2000. Controls on soil respiration: implications for climate change. Biogeochemistry 48: 1-6.

Rutigliano, F.A., R.D. Ascoli \& A.V. De Santo. 2004. Soil microbial metabolism and nutrient status in a Mediterranean area as affected by plant cover. Soil Biol. Biochem. 36: 1719-1729.

Santruckova, H. 1992. Microbial biomass, activity and soil respiration in relation to secondary succession. Pedobiologia 36: 341-350.

Schimel, D.S. 1995. Terrestrial ecosystems and the carbon cycle. Global Change Biol. 1: 77-91.

Schipper, L.A. et al. 2001. Changes in microbial heterotrophic diversity along five plant successional sequences. Soil Biol. Biochem. 33: 2093-2103.

Vance, E.D., P.C. Brookes \& D.S. Jenkinson. 1987. An extraction method for measuring soil microbial biomass C. Soil Biol. Biochem. 19: 703-707.

White, C. et al. 2005. Functional diversity of microbial communities in the mixed boreal plain forest of central Canada. Soil Biol. Biochem. 37: 1359-1372.

$\mathrm{Wu}$, Y. et al. 2001. Species diversity changes in subalpine coniferous forests of different restoration stages and 
their effects on soil properties. J. Plant Ecol. (Chinese Version) 25: 641-647 (In Chinese with English abstract). Zak, D.R. et al. 1994a. Plant production and soil microorganisms in late-successional ecosystems: a continental-scale study. Ecology 75: 2333-2347.
Zak, J.C. et al. 1994b. Functional diversity of microbial communities: a quantitative approach. Soil Biol. Biochem. 26: 1101-1108.

Zhu, P.F. \& D.R. Li. 1989. Forest Soil in Sichuan (in Chinese). Sichuan Science and Technology Press. Chengdu, China. 